\title{
Effects of continuous renal replacement therapy on linezolid pharmacokinetic/ pharmacodynamics: a systematic review
}

Gianluca Villa ${ }^{1,4^{*}}$, Paola Di Maggio ${ }^{1}$, A. Raffaele De Gaudio ${ }^{1}$, Andrea Novelli², Riccardo Antoniotti ${ }^{3}$, Enrico Fiaccadori ${ }^{3}$ and Chiara Adembri ${ }^{1}$

\begin{abstract}
Background: Major alterations in linezolid pharmacokinetic/pharmacodynamic (PK/PD) parameters might be expected in critically ill septic patients with acute kidney injury (AKI) who are undergoing continuous renal replacement therapy (CRRT). The present review is aimed at describing extracorporeal removal of linezolid and the main PK-PD parameter changes observed in critically ill septic patients with AKI, who are on CRRT.

Method: Citations published on PubMed up to January 2016 were systematically reviewed according to the preferred reporting items for systematic reviews and meta-analyses (PRISMA) statement. All authors assessed the methodological quality of the studies and consensus was used to ensure studies met inclusion criteria. In-vivo studies in adult patients with AKI treated with linezolid and on CRRT were considered eligible for the analysis only if operational settings of the CRRT machine, membrane type, linezolid blood concentrations and main PK-PD parameters were all clearly reported.

Results: Among 68 potentially relevant articles, only 9 were considered eligible for the analysis. Across these, 53 treatments were identified among the 49 patients included (46 treated with high-flux and 3 with high cut-off membranes). Continuous veno-venous hemofiltration (CWH) was the most frequent treatment performed amongst the studies. The extracorporeal clearance values of linezolid across the different modalities were 1.2-2.3 L/h for CWH, 0.9-2.2 L/h for hemodiafiltration and 2.3 L/h for hemodialysis, and large variability in PK/PD parameters was reported. The optimal area under the curve/minimum inhibitory concentration (AUC/MIC) ratio was reached for pathogens with an MIC of $4 \mathrm{mg} / \mathrm{L}$ in one study only.

Conclusions: Wide variability in linezolid PK/PD parameters has been observed across critically ill septic patients with AKI treated with CRRT. Particular attention should be paid to linezolid therapy in order to avoid antibiotic failure in these patients. Strategies to improve the effectiveness of this antimicrobial therapy (such as routine use of target drug monitoring, increased posology or extended infusion) should be carefully evaluated, both in clinical and research settings.
\end{abstract}

Keywords: Acute kidney injury, Adsorption, Clearance, Critical illness, High cut-off membranes, High-flux membranes, Linezolid, Sepsis

\footnotetext{
* Correspondence: gianlucavilla1@gmail.com

'Department of Health Science, Section of Anesthesiology and Intensive

Care, University of Florence, Largo Brambilla 3, Florence 50134, Italy

${ }^{4}$ Department of Anesthesia and Intensive Car, Azienda

Ospedaliero-Universitaria Careggi, Largo Brambilla 3, Florence 50134, Italy

Full list of author information is available at the end of the article
} 


\section{Background}

Sepsis is frequently observed in the intensive care unit (ICU), and it is one of the major causes of death among critically ill patients [1-4]. Infections in the ICU are frequently driven by multidrug-resistant strains [5], those sustained by Gram-positive bacteria such as methicillinresistant Staphylococcus aureus or vancomycin-resistant Enterococci being the most frequently observed $[2,6,7]$. Linezolid has been shown to be efficacious against these micro-organisms and, therefore it is frequently used in ICU patients $[7,8]$.

The volume of distribution $(\mathrm{Vd})$ of this low molecular weight (337 Da) oxazolidinone is $0.5-0.6 \mathrm{~L} / \mathrm{kg}$ in adult patients [9]; plasma elimination half-life $\left(t_{1 / 2}\right)$ ranges from 3.1 to $4.9 \mathrm{~h}$, and clearance is 6.4 to $14.8 \mathrm{~L} / \mathrm{h}$ [10]. Linezolid is metabolized by the liver to inactive metabolites excreted with the parent substance by the kidneys $[11,12]$. The parameters that best describe the antibiotic activity of linezolid are the time during which the plasma concentration exceeds the minimum inhibitory concentration (MIC) for the specific pathogen ( $\mathrm{T}>$ $\mathrm{MIC}$ ), and the area under the plasma concentration time curve over MIC ratio $\left(\mathrm{AUC}_{0-24} / \mathrm{MIC}\right)$ [13]. A $\mathrm{T}>\mathrm{MIC}$ of $\geq 85$ and an $\mathrm{AUC}_{0-24} / \mathrm{MIC}>100$ are required to exert maximal antimicrobial efficacy, and are associated with better clinical outcome in severely ill patients [13].

It is generally assumed that the recommended linezolid dose of $600 \mathrm{mg}$ every $12 \mathrm{~h}$ provides adequate plasma exposure to the antibiotic, and for this reason, along with the safety profile of the molecule, therapeutic drug monitoring (TDM) is deemed unnecessary $[14,15]$. However, wide variability in serum antibiotic concentrations has been reported among critically ill patients $[2,16]$, the concentrations below the therapeutic range being associated with development of antibiotic resistance and failure of antimicrobial therapy [17], while concentrations above this range may increase the risk of adverse reactions [18]. Possible drug-drug interactions may contribute to the variability of linezolid serum concentrations. Organ dysfunction and changes in vascular permeability typically observed among critically ill patients also explain the wide variation in antibiotic serum concentrations reported in the ICU $[16,19]$. For example, patients with severe sepsis or septic shock may frequently develop acute kidney injury (AKI) [20], which may affect drug disposition through changes in $\mathrm{Vd}$, protein binding and total body clearance $[21,22]$. Nonetheless, it is generally assumed that minimal pharmacokinetic/pharmacodynamic (PK/PD) alterations might be expected for linezolid during septic AKI, as linezolid renal clearance normally accounts for $<30 \%$ of total clearance and its $\mathrm{Vd}$ is minimally affected during sepsis due to the moderate lipophilic nature.

Continuous renal replacement therapy (CRRT), the most widely used modality in patients with sepsis and
AKI [23] may further reduce antibiotic blood concentrations by extracorporeal drug removal, increasing the risk of antimicrobial therapy failure [24-26]. Thus, in order to avoid suboptimal exposure, antibiotic therapy may frequently require dose adjustment during CRRT [24].

In patients on antibiotic treatment and CRRT, both specific antibiotic-related and CRRT-related characteristics are involved in extracorporeal drug removal [27]. In the specific case of linezolid, it seems likely that the molecule is efficiently removed by CRRT. As a matter of fact, the molecular weight is $337 \mathrm{Da}, 10$-fold to 100 -fold lower than the cutoff of the "high-flux" or "high cut-off" (HCO) membranes generally used in the ICU, the free fraction of the drug is about $70 \%$, and the $\mathrm{Vd}$ is relatively low $(0.5-0.6 \mathrm{~L} / \mathrm{Kg})$ [13]. Moreover, albumin-bound linezolid can also be removed by $\mathrm{HCO}$ membranes (cutoff $60 \mathrm{KDa}$ ) [28]. As far as the operational characteristics of CRRT are considered, the elimination of linezolid might be remarkable during both diffusion (due to the low molecular weight) and convection (owing to the characteristics of the most recent high-permeability membranes). Although the non-hydrophilic nature, the transmembrane removal of linezolid during CRRT is directly related to the effluent dose. An effluent dose of $25 \mathrm{ml} / \mathrm{Kg} / \mathrm{h}$ is nowadays recommended for critically ill patients with AKI, although higher doses may be prescribed for patients with sepsis and AKI (such as during high-volume hemofiltration), potentially leading to an increased removal of antibiotic. Furthermore, because most of the membranes used in the ICU have selective or unselective adsorption properties, small nonhydrophilic molecules such as linezolid may be easily bound and adsorbed from the circulation proportionally to serum concentration.

Thus, both antibiotic-related and CRRT-related characteristics may concomitantly and significantly affect the extracorporeal clearance of linezolid. As a consequence, relevant derangements of serum antibiotic levels are not unexpected in critically ill patients with sepsis and AKI who are undergoing CRRT, and failure to achieve adequate PK-PD targets may lead to ineffective pathogen eradication or increased risk of adverse effects [29].

Thus, this systematic review is aimed at (1) evaluating the effects of CRRT on linezolid removal, with special regard to the different modalities used in the ICU, and (2) describing and discussing the possible CCRT-related factors interfering with achievement of adequate PK-PD targets in critically ill patients with sepsis and AKI.

\section{Methods}

A systematic review was conducted in Pubmed, Embase, Scopus and Web of Science, according to the preferred reporting items for systematic reviews and meta-analyses (PRISMA) statement [30] to describe the main PK-PD 
parameters observed among critically ill patients with sepsis and AKI who were treated with linezolid and were on CRRT.

The search strategy for the literature selection used was: Linezolid AND (dialysis OR hemofiltration OR hemodiafiltration OR CVVH OR CVVHD OR CVVHDF OR "high cut-off" OR HCO-CVVHD OR "high volume hemofiltration" OR hemadsorption OR adsorption OR AN69 OR AN69ST OR toraymyxin OR cytosorb OR oxiris OR polyacrylonitrile OR polymethylmetacrylate OR polysulfone) AND (PK OR PD OR pharmacokinetic OR pharmacodynamic). The search included citations published up to January 2016; no filter was set on publication dates and language. Studies were eligible for review if they met the following inclusion criteria: (1) included every in-vivo prospective or retrospective study on adult patients with AKI treated with linezolid and CRRT; (2) the flows set in the CRRT machine and the membrane used were clearly indicated; (3) linezolid blood concentrations and main PK-PD parameters were clearly expressed. Studies were excluded if: (1) participants were aged $\leq 18$ years; (2) in-vitro data only were analyzed; (3) intermittent hemodialysis, sustained lowefficiency dialysis or peritoneal dialysis was used.

\section{Results}

The study selection chart is shown in Fig. 1. The literature search identified 193 potentially relevant articles, which were collected and checked against the eligibility criteria. Only 10 studies met the inclusion criteria and are summarized in Table 1. All studies were based on prospective data, and the papers comprised one congress presentation [31], five small case-series/case reports [9, 24, 32-34], three reports of observational studies [2, 26, 35] and only one report of a randomized clinical trial [36].

Sixty-seven CRRT treatments were identified across the 10 selected studies; amongst these, 60 were treated with high-flux membranes and 3 with $\mathrm{HCO}$ membranes. Continuous veno-venous hemofiltration $(\mathrm{CVVH})$ was the most frequent modality used ( 28 post-dilution, 4 pre-dilution over 67 treatments $47.8 \%$ ), with prescribed effluent doses of $30-35 \mathrm{ml} / \mathrm{kg} / \mathrm{h}$. On the other hand, 29 treatments over $67(43.3 \%)$ were performed with the continuous veno-venous hemodiafiltration (CVVHDF) modality, and the remaining 6 with continuous venovenous hemodialysis (CVVHD) (6/67 patients, 8.9\%), with a prescribed effluent dose of $30 \mathrm{ml} / \mathrm{kg} / \mathrm{h}$ for CVVHD and 27.7-41.2 $\mathrm{ml} / \mathrm{kg} / \mathrm{h}$ for CVVHDF. Data from Mauro et al. [34] were excluded because effluent dose values were considered too low $[11.2 \mathrm{ml} / \mathrm{kg} / \mathrm{h}]$. All but two studies provided information on extracorporeal linezolid removal achieved during CRRT (see Table 1).

\section{Discussion}

Linezolid is a moderately lipophilic drug with limited renal clearance of around 30\%. Accordingly, the influence of CRRT in its clearance might be expected to be only moderate. However, wide variability in PK parameters has been reported for linezolid in critically ill patients with sepsis [2, 37], especially when AKI coexists and RRT is needed [36]. This systematic review describes the parameters of extracorporeal removal of linezolid in the course of different modalities of CRRT, and of derangements in PK parameters in critically ill patients with sepsis and AKI, who are on CRRT.

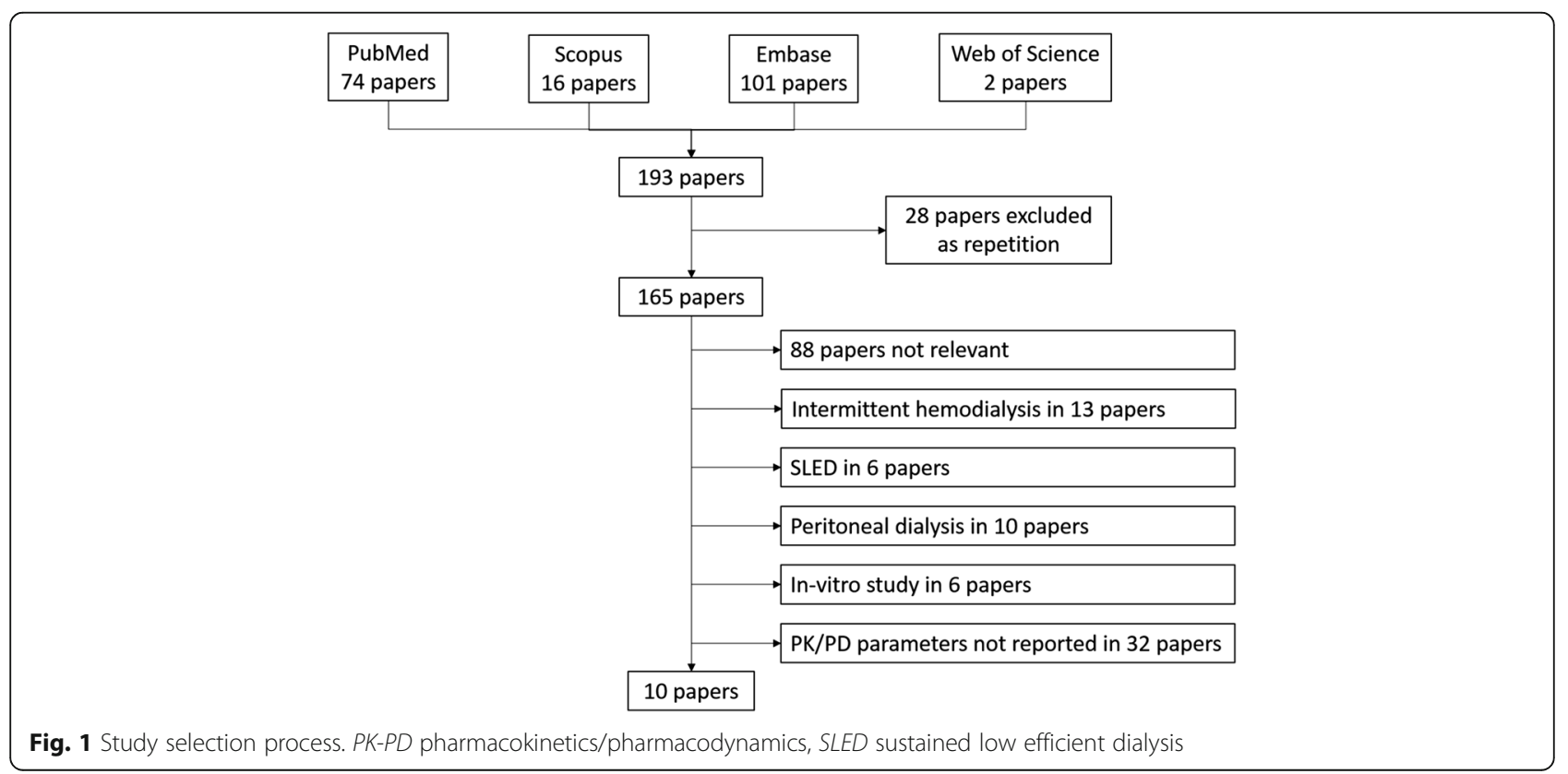


Table 1 Data on extracorporeal removal and PK/PD parameters obtained from literature analysis

\begin{tabular}{|c|c|c|c|c|c|c|c|}
\hline & & $\begin{array}{l}\text { 2016; Roger et al. } \\
\text { Prospective RCT }\end{array}$ & $\begin{array}{l}\text { 2005; Meyer et al. } \\
\text { Prospective } \\
\text { observational study }\end{array}$ & $\begin{array}{l}\text { 2005; Meyer et al. } \\
\text { Prospective } \\
\text { observational study }\end{array}$ & $\begin{array}{l}\text { 2004; Fiaccadori et al. } \\
\text { Prospective } \\
\text { observational study }\end{array}$ & $\begin{array}{l}\text { 2004; Pea et al. } \\
\text { Prospective } \\
\text { observational } \\
\text { case report }\end{array}$ & $\begin{array}{l}\text { 2016. Roger et al. } \\
\text { Prospective RCT }\end{array}$ \\
\hline \multirow[t]{15}{*}{ Treatment parameters } & Number of procedures & 8 & 7 & 13 & 2 & 2 & 9 \\
\hline & Treatment & CWH-post & CWH-post & CWH-post & CWH-pre & CWH-pre & CWHDF-post \\
\hline & \multirow[t]{3}{*}{ Membrane } & $\mathrm{HF}$ & $\mathrm{HF}$ & $\mathrm{HF}$ & $\mathrm{HF}$ & HF & $\mathrm{HF}$ \\
\hline & & PS & PS & PS & PAN & PS & PS \\
\hline & & $1.2 \mathrm{~m}^{2}$ & $1.2 \mathrm{~m}^{2}$ & $0.9 \mathrm{~m}^{2}$ & $1.65 \mathrm{~m}^{2}$ & $1.25 \mathrm{~m}^{2}$ & $1.2 \mathrm{~m}^{2}$ \\
\hline & $\mathrm{Qb}(\mathrm{ml} / \mathrm{min})$ & $200(185-245)$ & $189 \pm 15$ & $185 \pm 15$ & 150 & $125(120-130)$ & $200(165-200)$ \\
\hline & Qd (L/h) & & & & & & $1.14^{\mathrm{a}}$ \\
\hline & Qf (L/h) & $1.67^{\mathrm{a}}$ & $2.5 \pm 0.6$ & $2.3 \pm 0.4$ & $2.25(2-2.5)$ & $2(2-2)$ & $1.22^{\mathrm{a}}$ \\
\hline & $\mathrm{Qf}_{\mathrm{NET}}(\mathrm{ml} / \mathrm{h})$ & $0-200$ & & & & $115(80-150)$ & $0-200$ \\
\hline & $U F_{N E T}(L)$ & $3.6(0.2-4.3)$ & & & & & $1.1(0.4-1.6)$ \\
\hline & BW & $76(55-92)$ & $90 \pm 22^{a}$ & $83 \pm 15^{a}$ & $64(57-72)$ & $64.5(54-75)$ & $76(55-92)$ \\
\hline & Prescribed dose (ml/kg/h) & 30 & & & $35(35-35)$ & $33.6(29-39)$ & 30 \\
\hline & Effective time of treatment (min) & $715(697-751)$ & & & $675(630-720)$ & & $745(645-733)$ \\
\hline & APACHE ॥ & & $30 \pm 5(24-40)$ & $26 \pm 8(7-32)$ & $27(27-27)$ & & \\
\hline & SOFA at RRT initiation & $12(10-16)$ & & & & & $13(6-17)$ \\
\hline \multirow[t]{5}{*}{ Parameters of CRRT removal } & SA/SC (\%) & & $77 \pm 10(62-86)$ & $69 \pm 10(53-91)$ & $59(56-61)$ & $84(76-92)$ & \\
\hline & Qef $(L / h)$ & $1.98^{\mathrm{a}}$ & $2.5 \pm 0.6(1.5-3)$ & $2.3 \pm 0.4(1.5-3)$ & & $2.1(2.1-2.2)$ & $2.4^{\mathrm{a}}$ \\
\hline & Qef $(\mathrm{ml} / \mathrm{kg} / \mathrm{h})$ & $26^{\mathrm{a}}$ & $27.8^{\mathrm{a}}(16.3-40)$ & $27.7^{\mathrm{a}}(15-37.5)$ & & & $32.2^{\mathrm{a}}$ \\
\hline & $X_{\text {CRRT }}(\mathrm{mg})$ & & & & $89.9(75-105)$ & $237(160-314)$ & \\
\hline & $\mathrm{CL}_{\text {CRRT }}(\mathrm{L} / \mathrm{h})$ & & $2.3 \pm 0.9(1.3-4.3)$ & $1.6 \pm 0.5(0.9-2.7)$ & $1.2(1.2-1.3)$ & $1.4(1-2-1.6)$ & \\
\hline
\end{tabular}


Table 1 Data on extracorporeal removal and PK/PD parameters obtained from literature analysis (Continued)

\begin{tabular}{|c|c|c|c|c|c|c|c|}
\hline \multirow[t]{13}{*}{$\overline{\mathrm{PK}}$ and PD parameters } & $\mathrm{Cmax}(\mathrm{mg} / \mathrm{L})$ & $\sim 19^{\mathrm{b}}$ & $12.4 \pm 2.3(7.6-10.5)$ & $16.9 \pm 3.8(11.4-21.9)$ & $19.93(15.9-23.9)$ & $28.67(17.1-40.3)$ & $\sim 18^{\mathrm{b}}$ \\
\hline & $\mathrm{Cmin}(\mathrm{mg} / \mathrm{L})$ & $\sim 6^{\mathrm{b}}$ & $1.7 \pm 1.2(0.3-3.7)$ & $2 \pm 1.9(0.3-8)$ & & $14.1(6.5-21.7)$ & $\sim 4^{\mathrm{b}}$ \\
\hline & $\mathrm{T}_{1 / 2}(\mathrm{~h})$ & & $4.6 \pm 1.6(2.4-7.1)$ & $4.1 \pm 1.8(2.1-8.4)$ & $4.6(2.6-6.5)$ & $15.5(12.5--18.5)$ & \\
\hline & $A \cup C_{0-\infty}(\mathrm{mg} \cdot \mathrm{h} / \mathrm{L})$ & $227.9 \pm 115$ & $67.6(34-118)$ & $85.7(40-244)$ & & $444.6(219-669)$ & $227.9 \pm 115$ \\
\hline & $\mathrm{Vd}(\mathrm{L})$ & $26.5 \pm 10.3$ & $60.5 \pm 8.6(42.9-70.8)$ & $46.3 \pm 11.1(29.9-70.7)$ & $31.4(25.2-37.6)$ & $67.9(91.5-44.3)$ & $26.5 \pm 10.3$ \\
\hline & CLtot $(\mathrm{L} / \mathrm{h})$ & 4.5 & $10.4 \pm 3.9(5.1-17.6)$ & $8.7 \pm 3.0(2.5-14.7)$ & & $3.6(1.8-5.5)$ & 5.9 \\
\hline & $\mathrm{CL}_{\text {CRRT }} /$ CLtot (\%) & & $22.6^{\mathrm{a}}$ & $18.7^{\mathrm{a}}$ & & $48.89(28.7-69.1)$ & \\
\hline & $\mathrm{AUC}_{0-\infty} / \mathrm{MIC} 4 \mathrm{mg} / \mathrm{L}$ & & $33.8^{\mathrm{a}}$ & $42.8^{\mathrm{a}}$ & & $111.1(54-167)$ & \\
\hline & $\mathrm{AUC}_{0-\infty} / \mathrm{MIC} 2 \mathrm{mg} / \mathrm{L}$ & & $67.6^{\mathrm{a}}$ & $85.7^{\mathrm{a}}$ & & $222.3(109-334)$ & \\
\hline & AUCfree/MIC 4 mg/L & & & & & & \\
\hline & AUCfree/MIC 2 mg/L & & & & & & \\
\hline & $\% \mathrm{~T}>\mathrm{MIC} 4 \mathrm{mg} / \mathrm{L}$ & & $51 \pm 19(26-88)$ & $61 \pm 36(31-164)$ & & & \\
\hline & $\% \mathrm{~T}>\mathrm{MIC} 2 \mathrm{mg} / \mathrm{L}$ & & $89 \pm 32(46-137)$ & $96 \pm 50(48-234)$ & & & \\
\hline
\end{tabular}


Table 1 Data on extracorporeal removal and PK/PD parameters obtained from literature analysis (Continued)

\begin{tabular}{|c|c|c|c|c|c|c|c|c|}
\hline & & $\begin{array}{l}2012 \text { Carcelero et al. } \\
\text { Prospective } \\
\text { observational } \\
\text { case report }\end{array}$ & $\begin{array}{l}\text { 2006; Mauro et al. } \\
\text { Prospective } \\
\text { observational } \\
\text { case report }\end{array}$ & $\begin{array}{l}\text { 2014; Zoller et al. } \\
\text { Prospective } \\
\text { observational study }\end{array}$ & $\begin{array}{l}\text { 2012; Ide et al. } \\
\text { Abstract }\end{array}$ & $\begin{array}{l}\text { 2003; Kraft et al. } \\
\text { Prospective } \\
\text { observational } \\
\text { case report }\end{array}$ & $\begin{array}{l}\text { 2015; Villa et al. } \\
\text { Prospective } \\
\text { observational } \\
\text { case report }\end{array}$ & $\begin{array}{l}\text { 2014; Zoller et al. } \\
\text { Prospective } \\
\text { observational study }\end{array}$ \\
\hline \multirow[t]{15}{*}{ Treatment parameters } & Number of procedures & 2 & 1 & 2 & 14 & 1 & 3 & 3 \\
\hline & Treatment & CWHDF-pre & CWHDF-pre & CWHDF-? & CWHDF-? & CWHDF-? & CWHD & CWHD \\
\hline & \multirow[t]{3}{*}{ Membrane } & $\mathrm{HF}$ & $\mathrm{HF}$ & $\mathrm{HF}$ & $\mathrm{HF}$ & $\mathrm{HF}$ & \multirow[t]{2}{*}{ HCO PAES } & $\mathrm{HF}$ \\
\hline & & PAN & PAN & PS & PS & PS & & PS \\
\hline & & $0.9 \mathrm{~m}^{2}$ & $1 \mathrm{~m}^{2}$ & $1.4 \mathrm{~m}^{2}$ & $?$ & $1.6 \mathrm{~m}^{2}$ & $1.1 \mathrm{~m}^{2}$ & $1.8 \mathrm{~m}^{2}$ \\
\hline & $\mathrm{Qb}(\mathrm{ml} / \mathrm{min})$ & $165(150-180)$ & 200 & $130(100-150)$ & $79.3 \pm 2.7$ & 200 & 150 & $120(80-150)$ \\
\hline & Qd (L/h) & $1(1-1)$ & $1.2^{\mathrm{a}}$ & $1.4(1.2-1.5)$ & $0.52 \pm 0.31$ & 2 & $3^{a}(2.9-3.2)$ & \multirow[t]{2}{*}{$1.6(1-2)$} \\
\hline & Qf (L/h) & $1.5(1-2)$ & 0.2 & $1.5(1-2)$ & $0.33 \pm 0.15$ & 0.75 & - & \\
\hline & $\mathrm{Qf}_{\mathrm{NET}}(\mathrm{ml} / \mathrm{h})$ & \multicolumn{2}{|l|}{$100(50-150)$} & \multicolumn{2}{|l|}{$125(50-200)$} & 774 & 100 & \multirow[t]{2}{*}{$100(50-200)$} \\
\hline & $\mathrm{UF}_{\mathrm{NET}}(\mathrm{L})$ & & & & & & & \\
\hline & BW & $67.5(55-80)$ & 125 & & & 100 & $86(83-90)$ & \\
\hline & Prescribed dose $(\mathrm{m} / / \mathrm{kg} / \mathrm{h})$ & $41.2^{\mathrm{a}}(27-56)$ & 11.2 & & & $27.7^{\mathrm{a}}$ & 30 & \\
\hline & Effective time of treatment (min) & & & 3990 & & & & 5000 \\
\hline & APACHE II & $27(26-28)$ & & $31.5(28-35)$ & & & & $25(23-28)$ \\
\hline & SOFA at RRT initiation & $15(15-15)$ & & & & & $14.3(13-15)$ & \\
\hline \multirow[t]{5}{*}{ Parameters of CRRT removal } & SA/SC (\%) & $78(74-82)$ & & & $0.86 \pm 0.03$ & 79 & $74(66-80)$ & \\
\hline & Qef $(L / h)$ & $2.6^{\mathrm{a}}(2.2-3.1)$ & $1.4^{\mathrm{a}}$ & & & 2.8 & $3^{\mathrm{a}}(2.9-3.2)$ & \\
\hline & Qef (ml/kg/h) & & & & & & 30 & \\
\hline & $X_{\text {CRRT }}(\mathrm{mg})$ & $218.9(154-283)$ & 50.1 & & & & $197.6(154-266)$ & \\
\hline & $\mathrm{CL}_{\text {CRRT }}(\mathrm{L} / \mathrm{h})$ & $2.1(1.8-2.3)$ & 0.9 & & & 2.2 & $2.3(2.1-2.5)$ & \\
\hline
\end{tabular}


Table 1 Data on extracorporeal removal and PK/PD parameters obtained from literature analysis (Continued)

\begin{tabular}{|c|c|c|c|c|c|c|c|c|}
\hline \multirow[t]{13}{*}{ PK and PD parameters } & $C \max (\mathrm{mg} / \mathrm{L})$ & $18.85(16.5-21.2)$ & 15.3 & & & 16.4 & $17.13(10.4-23.5)$ & \\
\hline & $\mathrm{Cmin}(\mathrm{mg} / \mathrm{L})$ & $5.4(5.2-5.6)$ & 3.8 & $9.4(4.2-14.5)$ & & 7.2 & $6.2(2.9-10.3)$ & $8.5(3.7-18.7)$ \\
\hline & $T_{1 / 2}(h)$ & $6.2(4.9-7.4)$ & & & $8.78 \pm 3.74$ & 7.5 & $7.7(6.1-10.1)$ & \\
\hline & $A \cup C_{0-\infty}(m g \cdot h / L)$ & $263.5(214-312)$ & $105.8^{\mathrm{a}}$ & $303.9(165-442)$ & $247.9 \pm 107.8$ & & $208.2(95-352)$ & $283.1(144-453)$ \\
\hline & $V d(L)$ & $44(29.2-58.8)$ & & & $31 \pm 3.8$ & 49 & $48.9(39.9-57.9)$ & \\
\hline & CLtot (L/h) & $4.5(3.6-5.3)$ & 11.3 & & $294 \pm 1.38$ & 5.1 & $3.8(1.7-6.3)$ & \\
\hline & $\mathrm{CL}_{\text {CRRT }} / C L$ tot (\%) & $48.9^{\mathrm{a}}(33.9-63.9)$ & $7.9^{\mathrm{a}}$ & & & 43.1 & $67.1(39.6-100)$ & \\
\hline & $\mathrm{AUC}_{0-\infty} / \mathrm{MIC} 4 \mathrm{mg} / \mathrm{L}$ & $65.9^{\mathrm{a}}(53-78)$ & $26.5^{\mathrm{a}}$ & & & & $52.0(23-88)$ & \\
\hline & $\mathrm{AUC}_{0-\infty} / \mathrm{MIC} 2 \mathrm{mg} / \mathrm{L}$ & $131.8^{\mathrm{a}}(107-156)$ & $52.9^{\mathrm{a}}$ & & & & $104.1(47-176)$ & \\
\hline & AUCfree/MIC 4 mg/L & & & & & & $35.9(16-61)$ & \\
\hline & AUCfree/MIC 2 mg/L & & & & & & $71.8(33-122)$ & \\
\hline & $\% \mathrm{~T}>\mathrm{MIC} 4 \mathrm{mg} / \mathrm{L}$ & & & & & & & \\
\hline & $\%$ T > MIC $2 \mathrm{mg} / \mathrm{L}$ & & & & & & & \\
\hline
\end{tabular}

a Calculated from data presented in the original paper. ${ }^{b}$ Derived from figures presented in the original paper. $Q b$ blood flow, $Q d$ dialysate flow, $Q f$ replacement flow, $Q f_{N E T}$ net ultrafiltration flow, $U F_{N E T}$ net ultrafiltrate, $B W$ body weight, APACHE II Acute Physiology and Chronic Health Evaluation II, SOFA Sequential Organ Failure Assessment, SA/SC saturation coefficient or sieving coefficient, Qeff effluent flow, $X_{C R R T}$ total amount of drug eliminated by the extracorporeal treatment, $C L_{C R R T}$ extracorporeal clearance, $C$ max antibiotic maximum serum concentration, $C$ min antibiotic trough, $T_{1 / 2}$ elimination half-life, $A U C$ area under the curve, $V d$ volume of distribution, CLtot total clearance 


\section{Effect of dose and modality}

Although data considered for this review are only derived from studies of continuous treatments, wide variability in treatment modalities and operational parameters (such as blood, dialysate, replacement flows, etc.) was evident (see Table 1). Despite the wide variability observed, as well as treatment heterogeneity, extracorporeal clearance values for linezolid were similar across the different modalities: 1.2-2.3 L/h for CVVH, $0.9-2.2 \mathrm{~L} / \mathrm{h}$ for CVVHDF and $2.3 \mathrm{~L} / \mathrm{h}$ for CVVHD.

Although diffusive techniques should theoretically be characterized by higher extracorporeal clearance for low molecular-weight molecules (like linezolid) when compared with convective techniques, this effect was not observed across the studies assessed. Indeed, a number of factors might have influenced this finding, such as the variability in the flow set of the extracorporeal circuit and/or the specific geometrical characteristics of the various membranes, and the lack of a direct comparison of linezolid removal between the different techniques (diffusive vs convective). In fact, only one study [36] directly compared the PK linezolid parameters in $\mathrm{CVVH}$ and CVVHDF. Particularly, this study compared linezolid PK parameters in critically ill patients with sepsis and AKI treated with CVVH or CVVHDF at the same prescribed effluent dose $(30 \mathrm{ml} / \mathrm{kg} / \mathrm{h})$ [36]. Unfortunately, the authors reported few data specifically for patients on CVVH or CVVHDF. Indeed, excluding the total drug clearance, no other PK parameters were reported or formally compared between the two groups. Furthermore, when comparing the total body clearance, extracorporeal clearance was not detailed (i.e. CVVH or CVVHDF clearance). A $20 \%$ reduction in total linezolid clearance ( 5.9 vs $4.5 \mathrm{~L} / \mathrm{h}, p=0.39$ ) was observed in the group of patients treated with $\mathrm{CVVH}$ as compared to CVVHDF, making this finding in line with the concept of higher extracorporeal clearance achievable for small molecules through diffusive techniques. However, although a total effluent dose of $30 \mathrm{ml} / \mathrm{kg} / \mathrm{h}$ was reported in the method section for both groups of patients, the CVVH group was in fact treated with a $20 \%$ lower total effective effluent dose (Qeff) compared to the CVVHDF group ( $26 \mathrm{ml} / \mathrm{kg} / \mathrm{h}$ vs $32.17 \mathrm{ml} / \mathrm{kg} / \mathrm{h}$ ) (See Table 1). As the extracorporeal clearance is defined as the sieving coefficient (SC) (or saturation coefficient, SA, for CVVHDF) multiplied by Qeff, it is not surprising that the total linezolid clearance was $20 \%$ lower in the CVVH group as compared to CVVHDF (See Table 1). Therefore, in these conditions, it is not possible to infer that removal by diffusive techniques is more efficient than by convective techniques.

\section{Effect of membrane characteristics}

The analysis of the extracorporeal drug removal and PK derangements due to CRRT should also take into account the characteristics of the membrane used, in terms of surface area, composition and pore diameter [38].

Higher extracorporeal clearance of linezolid has been documented in patients treated with larger filters (1.2 vs $0.9 \mathrm{~m}^{2}$ ) [35]. Particularly, although these two groups of patients were treated with the same modality and treatment setting (CVVH in post-dilution, with a blood flow of 185-189 $\mathrm{ml} /$ minute and effluent dose of $27.7 \mathrm{ml} / \mathrm{kg} / \mathrm{h}$ ), extracorporeal clearance was higher when the larger filter was used $(2.34 \mathrm{~L} / \mathrm{h}$ vs $1.63 \mathrm{~L} / \mathrm{h})$ (see Table 1). Furthermore, membrane composition may also influence drug removal by adsorption. As the most common membranes used in the ICU, such as polymethylmethacrylate or polyacrylonitrile, also have unselective adsorption properties, further studies should take this issue into consideration. In fact, although membrane drug adsorption is commonly underrated, it is usually rapid and not reversible, leading to a reduction of antibiotic concentrations [39]. For example, Kraft et al. [32] and Carcelero et al. [24], using the same treatment modality (CVVHDF) and the same operational setting (effluent flow 2.6-2.7 L/h), observed the same extracorporeal clearance of linezolid $(2.05-2.19 \mathrm{~L} / \mathrm{h})$, despite the former having used a polysulfone membrane with a twofold surface area $\left(1.6 \mathrm{~m}^{2}\right)$ compared to the acrylonitrile membrane used by the latter $\left(0.9 \mathrm{~m}^{2}\right)$ (see Table 1$)$. In this case, the reduced transmembrane clearance obtained by the smaller acrylonitrile surface might have been compensated by its higher adsorption properties; as a consequence, the total extracorporeal clearance was similar to that observed with polysulfone membrane with by a broader surface area but lower adsorption capacity.

In the case of linezolid, a molecule with quite a low radius as compared to the large cut-off of the hemodiafilters commonly used in the ICU (high flux and/or HCO membranes), pore size is likely to be scarcely relevant. For example, Villa et al. observed a mean SA equal to 0.80 with HCO membranes used in CVVHD [9]; this value was similar to SA or SC reported in other studies in which patients with AKI were treated with hemodiafiltration or hemofiltration with standard high-flux membranes. In particular, Kraft et al. calculated SA values ranging from 0.77 to 0.81 during CVVHDF [32] and similar results were reported by several authors for the SC obtained during CVVH [24, 33-35]. The removal of linezolid calculated by Villa et al. during HCO-CVVHD was similar to that reported in the literature for high-flux membranes [9], even though an increase in transmembrane linezolid loss should be expected with $\mathrm{HCO}$ if convective clearance is applied during the treatment (see aforementioned).

\section{Effect of patients' clinical characteristics}

Apart from the key role of CRRT in determining PK antibiotic changes, even the critically ill status may be 
playing a major role [19]. Indeed, increased drug clearance was reported in patients with low SOFA scores [36]. Commonly, in patients with sepsis and AKI, who are undergoing CRRT and are on vasopressor support (as in the study by Roger et al.) [36], lower SOFA scores are mainly correlated with improved neurologic, respiratory and/or liver function. As $40 \%$ of the drug is usually metabolized and inactivated by the liver, it is not surprising that lower SOFA scores were associated with higher linezolid clearance.

The results were similar in our previous study performed in patients with sepsis and AKI treated with standard doses of linezolid and hemodialysis with $\mathrm{HCO}$ membranes [9], in which impaired liver function was associated with decreased corporeal drug clearance. As the total clearance $\left(\mathrm{CL}_{\text {tot }}\right)$ is the sum of the extracorporeal $\left(\mathrm{CL}_{\mathrm{HCO}}\right)$ and non CRRT clearance, a subsequent increased ratio between extracorporeal and total linezolid clearance $\left(\mathrm{CL}_{\mathrm{HCO}} / \mathrm{CL}_{\mathrm{tot}}\right)$ was observed in critically ill patients with AKI and severe liver dysfunction. In these conditions, the $\mathrm{CL}_{\mathrm{HCO}} / \mathrm{CL}_{\text {tot }}$ value is likely to be higher than $30 \%$, only apparently identifying a treatment in which the extracorporeal clearance is critical for the total drug removal, potentially affecting its PK/PD parameters $[9,40]$. In these conditions, in line with Roger's results, the severity of the condition may influence the drug disposition.

\section{Results for PK/PD parameters}

Cmax and Cmin values are highly variable among patients considered in this review, as they ranged from 12.4 to $28.6 \mathrm{mg} / \mathrm{L}$ and from 1.7 to $14 \mathrm{mg} / \mathrm{L}$, respectively (Table 1). Although Cmax values are similar or higher than those reported in the literature for healthy subjects, patients with renal impairment and ICU patients $[13,16]$, the Cmin values were lower than those reported for the same populations. Similarly, total clearance and volume of distribution values observed in the overall population were also highly variable (from 3.64 to $11.3 \mathrm{~L} / \mathrm{h}$ and from 26.5 to $67.89 \mathrm{~L}$, respectively) (Table 1). Patients' comorbidities and organ dysfunction may significantly affect these parameters. For instance, the large Vd calculated by Roger et al. in the CVVH group might be explained by the likely greater fluid overload observed in these patients with respect to the CVVHDF group. Indeed, the net ultrafiltration fluid removal set in the CVVH group was about four times that in the CVVHDF group (net ultrafiltration 1100 vs $3620 \mathrm{ml}$ respectively, see Table 1 ).

All these observations suggest that the clinical features of critically ill patients with sepsis and AKI treated with CRRT may play a key role in the achievement of appropriate PK/PD parameters for linezolid [36]. When considering pathogens with an MIC value of $2.0 \mathrm{mg} / \mathrm{L}$ for linezolid, two of the reviewed studies reported AUC/ MIC ratios constantly below 85 , and therefore not adequate for a clinical cure. What is more, when considering pathogens with an MIC value of $4.0 \mathrm{mg} / \mathrm{L}$, only one study reported the optimal AUC/MIC ratio [15]. Therefore, the failure to achieve the optimal PK/PD targets for linezolid might increase the likelihood of emergence of microbial resistance and consequent clinical failure [36]. Furthermore, increased dosing of linezolid in critically ill patients with sepsis and AKI undergoing CRRT could expose patients to adverse effects. Thrombocytopenia has been reported as a frequent side effect of linezolid, especially in patients with renal dysfunction, in patients who develop heparin-induced thrombocytopenia (HIT) during anticoagulation treatment for CRRT, and in patients whose blood is exposed to low compatibility membranes.

Another partial explanation for our results may be related to linezolid drug-drug interactions. Drug-drug interaction with linezolid has been reported by several authors [14, 41-47] Rifampin can markedly decrease the linezolid serum concentration (thus affecting the probability of target attainment for clinical success). On the contrary, the majority of drugs interacting with linezolid, such as P-glycoprotein and CYP isoform inhibitors (i.e. protein pump inhibitors, calcium channel blockers, macrolides and so on), increase linezolid serum levels and therefore do not contribute to increased risk of clinical failure. Unfortunately, no information on pharmacological treatments is available for patients in the studies analyzed for this systematic review.

In this context, if optimal linezolid PK/PD targets are not achieved in patients with sepsis and AKI treated with CRRT, clinical failure of antibiotic treatment is more likely, especially in the case of infections sustained by microorganisms with higher MIC values (e.g. Enterococci). Therefore, although conflicting opinions are reported on the use of TDM for linezolid therapy monitoring in critically ill patients with sepsis, it is however, to be recommended for these patients, especially if they develop AKI and eventually CRRT is to be started [2].

\section{Conclusions}

Wide variability in linezolid PK/PD parameters has been observed across critically ill patients with sepsis, especially those with AKI treated with CRRT. The effects of the extracorporeal treatment on antibiotic PK/PD target achievement should be carefully considered and adapted to the individual patient's physio-pathological characteristics. Similar to other serious conditions, a TDM could be an effective method to ensure adequate antibiotic exposure, especially in critically ill patients with sepsis and AKI, who are on CRRT. If TDM is not routinely available, increased posology of linezolid might be alternatively 
considered for these patients during treatments performed with high diffusive/convective and/or adsorption clearance. Furthermore, different modalities of administration might be considered, such as continuous infusion.

\section{Abbreviations}

AKI: acute kidney injury; APACHE II: Acute Physiology and Chronic Health Evaluation II; $\mathrm{AUC}_{0-24}$ : area under the plasma concentration time curve; BW: body weight; $\mathrm{CL}_{\text {CRRT: }}$ extracorporeal clearance; CLtot: total clearance; Cmax: antibiotic maximum serum concentration; Cmin: antibiotic trough; CRRT: continuous renal replacement therapy; $\mathrm{CWH}$ : continuous veno-venous hemofiltration; CWHD: continuous veno-venous hemodialysis; CWHDF: continuous veno-venous hemodiafiltration; HCO: high cut-off membranes; ICU: intensive care unit; MIC: minimum inhibitory concentration; PK-PD: pharmacokinetic/pharmacodynamics; PRISMA: preferred reporting items for systematic reviews and meta-analyses; Qb: blood flow; Qd: dialysate

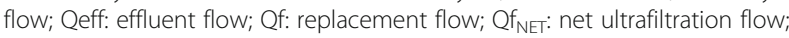
SA/SC: saturation coefficient or sieving coefficient; SOFA: Sequential Organ Failure Assessment; $\mathrm{t}_{1 / 2}$ : plasma elimination half-life; TDM: therapeutic drug monitoring; UF $F_{\text {NET: }}$ net ultrafiltrate; $V$ d: volume of distribution; $X_{\text {CRRT: }}$ total amount of drug eliminated by the extracorporeal treatment

\section{Funding}

No sources of funding for the research reported should be declared.

\section{Authors' contributions}

GV and PDM performed the literature research and drafted the manuscript ARDG, EF, RA, AN and CA conceived of the study, and participated in its design, helped to draft the manuscript and gave the final approval of the version to be published. All authors read and approved the final manuscript.

\section{Competing interests}

PDM is a permanent employee of Norgine Pharmaceuticals Limited.

\section{Consent for publication}

Not applicable.

\section{Ethical approval and consent to participate}

Not applicable.

\section{Author details}

'Department of Health Science, Section of Anesthesiology and Intensive Care, University of Florence, Largo Brambilla 3, Florence 50134, Italy. ${ }^{2}$ Department of Health Sciences, Section of Clinical Pharmacology and Oncology, University of Florence, Viale Pieraccini 18, Florence 50139, Italy. ${ }^{3}$ Acute and Chronic Renal Failure Unit, Department of Clinical and Experimental Medicine, Parma University Medical School, Via Gramsci 14, Parma 43100, Italy. ${ }^{4}$ Department of Anesthesia and Intensive Car, Azienda Ospedaliero-Universitaria Careggi, Largo Brambilla 3, Florence 50134, Italy.

\section{Received: 9 May 2016 Accepted: 31 October 2016}

\section{Published online: 19 November 2016}

\section{References}

1. Kim WY, Huh JW, Lim C-M, Koh Y, Hong S-B. Analysis of progression in risk, injury, failure, loss, and end-stage renal disease classification on outcome in patients with severe sepsis and septic shock. J Crit Care. 2012;27:104.e1-7. http://dx.doi.org/10.1016/j.jcrc.2011.04.005

2. Zoller M, Maier B, Hornuss C, Neugebauer C, Döbbeler G, Nagel D, et al. Variability of linezolid concentrations after standard dosing in critically ill patients: a prospective observational study. Crit Care. 2014;18:R148. http://www.ncbi.nlm.nih.gov/pubmed/25011656.

3. Gaieski D, Edwards J, Kallan M, Carr B. Benchmarking the incidence and mortality of severe sepsis in the united states. Crit Care Med. 2013;41:1167-74. Available from: https://www.ncbinlm.nih.gov/pubmed/23442987.

4. Fleischmann C, Scherag A, Adhikari NK, Hartog CS, Tsaganos T, Schlattmann P et al. Assessment of global incidence and mortality of hospital-treated sepsis current estimates and limitations. Am J Respir Crit Care Med. 2016;193:259-72.

5. Chelazzi C, Pettini E, Villa G, De Gaudio AR. Epidemiology, associated factors and outcomes of ICU-acquired infections caused by Gram-negative bacteria in critically ill patients: an observational, retrospective study. BMC Anesthesiol. 2015;15:125. Available from: http://www.biomedcentral.com/1471-2253/15/125.

6. Appelbaum PC. The emergence of vancomycin-intermediate and vancomycin-resistant Staphylococcus aureus. Clin Microbiol Infect. 2006;12: 16-23. Available from: http://dx.doi.org/10.1111/j.1469-0691.2006.01344.X.

7. Cepeda JA, Whitehouse T, Cooper B, Hails J, Jones K, Kwaku F, et al. Linezolid versus teicoplanin in the treatment of Gram-positive infections in the critically ill: a randomized, double-blind, multicentre study. J Antimicrob Chemother. 2004;53:345-55.

8. Deryke CA, Lodise TP, Rybak MJ, McKinnon PS. Epidemiology, treatment, and outcomes of nosocomial bacteremic Staphylococcus aureus pneumonia. Chest. 2005;128:1414-22. Available from: http://journal.publications. chestnet.org/data/Journals/CHEST/22030/1414.pdf.

9. Villa G, Cassetta MI, Tofani L, Valente S, Chelazzi C, Falsini S, et al. Linezolid extracorporeal removal during haemodialysis with high cut-off membrane in critically ill patients. Int J Antimicrob Agents. 2015;46:465-8. Available from: http://fulltext.study/preview/pdf/3358583.pdf.

10. Di Paolo A, Malacarne P, Guidotti E, Danesi R, Del Tacca M. Pharmacological issues of linezolid: an updated critical review. Clin Pharmacokinet. 2010; 49:439-47.

11. Dryden MS. Linezolid pharmacokinetics and pharmacodynamics in clinical treatment. J Antimicrob Chemother. 2011;66:7-15.

12. Slatter JG, Stalker DJ, Feenstra KL, Welshman IR, Bruss JB, Sams JP, et al. Pharmacokinetics, metabolism, and excretion of linezolid following an oral dose of [(14)C]linezolid to healthy human subjects. Drug Metab Dispos. 2001;29:1136-45.

13. Macgowan AP. Pharmacokinetic and pharmacodynamic profile of linezolid in healthy volunteers and patients with Gram-positive infections. J Antimicrob Chemother. 2003;51:17-25.

14. Pea F, Furlanut M, Cojutti P, Cristini F, Zamparini E, Franceschi L, et al. Therapeutic drug monitoring of linezolid: A retrospective monocentric analysis. Antimicrob Agents Chemother. 2010;54:4605-10.

15. Stalker D, Jungbluth G. Clinical pharmacokinetics of linezolid, a novel oxazolidinone antibacterial. Clin Pharmacokinet. 2003;42:1129-40.

16. Adembri C, Fallani S, Cassetta MI, Arrigucci S, Ottaviano A, Pecile P, et al. Linezolid pharmacokinetic/pharmacodynamic profile in critically ill septic patients: intermittent versus continuous infusion. Int J Antimicrob Agents. 2008;31:122-9. http://www.ncbi.nlm.nih.gov/pubmed/18055183.

17. Thilesen C, Bjørang O, Skrede T, Aronsen T, Aasnaes B, Sundsfjord A, et al. Emergence of mutation-based linezolid-resistant invasive Enterococcus faecalis in a haemodialysis patient in Norway. APMIS. 2014;122:83-4.

18. Lin Y-H, Wu V-C, Tsai I-J, Ho Y-L, Hwang J-J, Tsau Y-K, et al. High frequency of linezolid-associated thrombocytopenia among patients with renal insufficiency. Int J Antimicrob Agents. 2006;28:345-51. http://www.ncbi.nlm. nih.gov/pubmed/16935472.

19. Blot SI, Pea F, Lipman J. The effect of pathophysiology on pharmacokinetics in the critically ill patient - concepts appraised by the example of antimicrobial agents. Adv Drug Deliv Rev. 2014;77:3-11. Available from: http://dx.doi.org/10.1016/j.addr.2014.07.006.

20. Cardinal-fernández P, Ferruelo A, El-assar M, Santiago C, Gómez-gallego F, Martín-pellicer A, et al. Genetic predisposition to acute kidney injury induced by severe sepsis. J Crit Care. 2013;28:365-70. Available from: https://www.ncbi.nlm.nih.gov/pmc/articles/PMC4667497/.

21. Bugge JF. Influence of renal replacement therapy on pharmacokinetics in critically ill patients. Best Pr Res Clin Anaesthesiol. 2004;18:175-87. http://www.ncbi.nlm.nih.gov/pubmed/14760881.

22. Eyler RF, Mueller BA. Antibiotic dosing in critically ill patients with acute kidney injury. Nat Rev Nephrol. 2011;7:226-35. http://www.ncbi.nlm.nih.gov/ pubmed/21343897.

23. Oh HJ, Shin DH, Lee MJ, Koo HM, Doh FM, Kim HR, et al. Early initiation of continuous renal replacement therapy improves patient survival in severe progressive septic acute. J Crit Care. 2012;27:743. http://dx.doi.org/10.1016/j. jcrc.2012.08.001.

24. Carcelero E, Soy D, Guerrero L, Poch E, Fernandez J, Castro P, et al. Linezolid pharmacokinetics in patients with acute renal failure undergoing continuous venovenous hemodiafiltration. J Clin Pharmacol. 2012;52:1430-5. http://www. ncbi.nlm.nih.gov/pubmed/21960670.

25. Smuszkiewicz P, Szałek E, Tomczak H, Grześkowiak E. Continuous infusion of antibiotics in critically ill patients. Curr Clin Pharmacol. 2013;8:13-24.

26. Fiaccadori E, Maggiore U, Rotelli C, Giacosa R, Parenti E, Picetti E, et al. Removal of linezolid by conventional intermittent hemodialysis, sustained 
low-efficiency dialysis, or continuous venovenous hemofiltration in patients with acute renal failure. Crit Care Med. 2004;32:2437-42. Available from: https://www.ncbi.nlm.nih.gov/pubmed/15599148.

27. Smith BS, Yogaratnam D, Levasseur-Franklin KE, Forni A, Fong J. Introduction to drug pharmacokinetics in the critically ill patient. Chest. 2012;141:1327-36.

28. Villa G, Zaragoza JJ, Sharma A, Neri M, De Gaudio AR, Ronco C. Cytokine removal with high cut-off membrane: review of literature. Blood Purif. 2014;38:167-73. http://www.ncbi.nlm.nih.gov/pubmed/25471681.

29. Drusano GL. Antimicrobial pharmacodynamics: critical interactions of "bug and drug". Nat Rev Microbiol. 2004;2:289-300.

30. Liberati A, Altman DG, Tetzlaff J, Mulrow C, Gøtzsche PC, loannidis JPA, et al. The PRISMA statement for reporting systematic reviews and meta-analyses of studies that evaluate health care interventions: explanation and elaboration. PLoS Med. 2009;6:e1000100. Available from: http://www.bmj. com/content/339/bmj.b2700.

31. Ide T, Hori N, Ikeda Y, Takeda K, Nishi S. Elimination of linezolid in patients undergoing low-flow continuous venovenous haemodiafiltration. Crit Care. 2012;16(suppl 1):P68. https:/www.ncbi.nlm.nih.gov/pmc/articles/PMC3363486/.

32. Kraft M, Pasko D, DePestel D, Ellis J, Peloquin C, Mueller B. Linezolid clearance during continuous venovenous hemodiafiltration: a case report. Pharmacotherapy. 2013;23:1071-5.

33. Pea F, Viale P, Lugano M, Pavan F, Scudeller L, Della Rocca G, et al. Linezolid disposition after standard dosages in critically ill patients undergoing continuous venovenous hemofiltration: a report of 2 cases. Am J Kidney Dis. 2004;44:1097-102. Available from: https://www.ncbi.nlm.nih.gov/pubmed/ 15558532.

34. Mauro LS, Peloquin CA, Schmude K, Assaly R, Malhotra D. Clearance of linezolid via continuous venovenous hemodiafiltration. Am J Kidney Dis. 2006;47:e83-6. https://www.ncbi.nlm.nih.gov/pubmed/16731287.

35. Meyer B, Kornek GV, Nikfardjam M, Karth GD, Heinz G, Locker GJ, et al. Multiple-dose pharmacokinetics of linezolid during continuous venovenous haemofiltration. J Antimicrob Chemother. 2005;56:172-9. https://www.ncbi. nlm.nih.gov/pubmed/15905303.

36. Roger C, Muller L, Wallis SC, Louart B, Saissi G, Lipman J, et al. Population pharmacokinetics of linezolid in critically ill patients on renal replacement therapy: comparison of equal doses in continuous venovenous haemofiltration and continuous venovenous haemodiafiltration. J Antimicrob Chemother. 2015. Available from: https://www.ncbi.nlm.nih.gov/pubmed/26538503.

37. Morata L, Cuesta M, Rojas JF, Rodriguez S, Brunet M, Casals G, et al. Risk factors for a low linezolid trough plasma concentration in acute infections. Antimicrob Agents Chemother. 2013;57:1913-7.

38. Jamal JA, Mueller BA, Choi GYS, Lipman J, Roberts JA. How can we ensure effective antibiotic dosing in critically ill patients receiving different types of renal replacement therapy? Diagn Microbiol Infect Dis. 2015;82:92-103.

39. Lam P, Tian Q, Ip M, Gomersall CD. In vitro adsorption of gentamicin and netilmicin by polyacrylonitrile and polyamide hemofiltration filters. Antimicrob Agents Chemother. 2010;54:963-5. Available from: http://www. pubmedcentral.nih.gov/articlerender.fcgi?artid=2812183\&tool= pmcentrez\&rendertype=abstract.

40. Markou N, Fousteri M, Markantonis SL, Zidianakis B, Hroni D, Boutzouka E, et al. Colistin pharmacokinetics in intensive care unit patients on continuous venovenous haemodiafiltration: an observational study. J Antimicrob Chemother. 2012;67:2459-62. http://ovidsp.ovid.com/ovidweb. cgi? T=JS\&CSC $=$ Y\&NEWS=N\&PAGE=fulltext\&D=medl\&AN=22790220\nhttp:// sfx.scholarsportal.info/uhn?sid=OVID:medline\&id=pmid:22790220\&id=doi:10. 1093/jac/dks257\&issn=0305-7453\&isbn=\&volume=67\&issue=10\&spage $=$ 2459\&pages $=2459-62 \&$ date $=201$.

41. Katoh M, Nakajima M, Shimada N, Yamazaki H, Yokoi T. Inhibition of human cytochrome $\mathrm{P} 450$ enzymes by 1,4-dihydropyridine calcium antagonists: prediction of in vivo drug-drug interactions. Eur J Clin Pharmacol. 2000;55: 843-52.

42. Yamreudeewong W, DeBisschop M, Martin LG, Lower DL. Potentially significant drug interactions of class III antiarrhythmic drugs. Drug Saf. 2003;26:421-38.

43. Pauli-Magnus C, Rekersbrink S, Klotz U, Fromm MF. Interaction of omeprazole, lansoprazole and pantoprazole with P-glycoprotein. Naunyn Schmiedebergs Arch Pharmacol. 2001;364:551-7.

44. Bolhuis MS, van Altena R, Uges DRA, van der Werf TS, Kosterink JGW, Alffenaar J-WC. Clarithromycin significantly increases linezolid serum concentrations. Antimicrob Agents Chemother. 2010:54;5418-9
45. Gandelman K, Zhu T, Fahmi OA, Glue P, Lian K, Obach RS, et al. Unexpected effect of rifampin on the pharmacokinetics of linezolid: in silico and in vitro approaches to explain its mechanism. J Clin Pharmacol. 2011;51:229-36.

46. Cojutti P, Maximova N, Crichiutti G, Isola M, Pea F. Pharmacokinetic/ pharmacodynamic evaluation of linezolid in hospitalized paediatric patients: a step toward dose optimization by means of therapeutic drug monitoring and Monte Carlo simulation. J Antimicrob Chemother. 2015;70:198-206.

47. Egle H, Trittler R, Klimmerer K, Lemmen S. Linezolid and rifampin: Drug interaction contrary to expectations? Clin Pharmacol Ther. 2005;77:451. Available from: https://www.ncbi.nlm.nih.gov/pubmed/15900290.

\section{Submit your next manuscript to BioMed Central and we will help you at every step:}

- We accept pre-submission inquiries

- Our selector tool helps you to find the most relevant journal

- We provide round the clock customer support

- Convenient online submission

- Thorough peer review

- Inclusion in PubMed and all major indexing services

- Maximum visibility for your research

Submit your manuscript at www.biomedcentral.com/submit
C Biomed Central 